\title{
SANTO AGOSTINHO E A FENOMENOLOGIA: 0 CONCEITO DE ATENÇÃO
}

\author{
Saint Augustine and phenomenology: the concept of attention \\ San Agustín y la fenomenología: la concepción de la atención
}

\begin{abstract}
Resumo: O objetivo deste artigo é apresentar como alguns tópicos centrais da fenomenologia se encontram na concepção agostiniana do espírito humano. Em particular, analisaremos os conceitos intenção ou atenção (intentio), de cogito e de reflexão em Agostinho. Como corpus de análise foi usada A Trindade, por se tratar de uma obra de maturidade do autor. Inicialmente, apresentamos o papel que a atenção joga na percepção, na retenção memorativa e na evocação dos conteúdos da memória. Em seguida, discutimos como Agostinho articula atenção e vontade na dinâmica do cogito. Posteriormente, buscamos apontar como a distinção agostiniana entre pensar em si e conhecer a si antecipa a discussão fenomenológica atual entre autoconsciência pré-reflexiva e consciência reflexiva. Finalmente, examinamos a maneira como Agostinho aborda o problema da possibilidade da reflexão, como fonte epistêmica do conhecimento de si. Palavras-chave: Agostinho, fenomenologia, cogito, reflexão, intencionalidade
\end{abstract}

\begin{abstract}
The aim of this article is to present how some central topics of phenomenology are found in the Augustinian conception of the human spirit. In particular, we will analyze the concepts of intention or attention (intentio), cogito and reflection in Augustine. As a corpus of analysis, the Trinity was used. Initially, we present the role that attention plays in the perception, in the memory retention and in the evocation of the contents of memory. Next, we discuss how Augustine articulates attention and will in the cogito dynamics. Subsequently, we seek to point out the Augustinian distinction between thinking about oneself and knowing oneself anticipates the current phenomenological discussion between pre-reflective self-consciousness and reflective consciousness. Finally, we examine the way Augustine addresses the problem of the possibility of reflection, as an epistemic source of self-knowledge.
\end{abstract}

Key words: Augustine, phenomenology, cogito, reflection, intentionality

Resumen: El objetivo de este artículo es presentar como algunos tópicos centrales de la fenomenología se encuentran en la concepción agustiniana del espíritu humano. En particular, analizaremos los conceptos intención o atención (intentio), de reflexión y reflexión en Agustín. Como corpus de análisis fue usada La Trinidad, por tratarse de una obra de madurez del autor. Inicialmente, presentamos el papel que la atención juega en la percepción, en la retención memorial y en la evocación de los contenidos de la memoria. A continuación, discutimos cómo Agustín articula atención y voluntad en la dinámica del cogito. Posteriormente, buscamos apuntar cómo la distinción agustina entre pensar en sí y conocer a sí anticipa la discusión fenomenológica actual entre autoconciencia pre-reflexiva y conciencia reflexiva. Finalmente, examinamos la manera como Agustín aborda el problema de la posibilidad de la reflexión, como fuente epistémica del conocimiento de sí.

Palabras clave: Agustín, fenomenología, reflexión, reflexión, intencionalidade

\section{Introdução}

É amplamente conhecida na literatura especializada as poucas, mas bastante elogiosas, referências que Husserl faz a Santo Agostinho, particularmente, em duas passagens. A primeira delas se encontra nas Lições sobre a consciência interna do tempo, onde Husserl escreve:

Os capítulos 14-28 do Livro XI das Confissões devem ainda hoje ser profundamente estudados por quem se ocupe com o problema do tempo. Porquanto, nestas coisas, a época moderna, orgulhosa de seu saber, nada mais grandioso e mais considerável trouxe do que este grande, e na verdade, incansável pensador. Ainda hoje se pode dizer com Santo Agostinho: si nemo a me quaerat, scio, si quarenti explicare velim, nescio ${ }^{1}$. (Husserl, 1994, p.37)

Para Husserl, a importância das concepções de Agostinho sobre o tempo encontra-se sobretudo no fato de que este último buscou descrever o tempo não como uma realidade objetiva, mas como uma distensão do espírito (distentio animi). No livro Onze das Confissões, Agostinho abordou o tempo de maneira peculiar. Ao contrário de uma abordagem clássica, que concebia o tempo como realidade em si, o foco de Agostinho foi abordar o tempo a partir da experiência do tempo. É esse acento, naquilo que hoje se denomina de subjetividade, o núcleo dos elogios de Husserl ao padre da Igreja. A segunda menção conhecida de Husserl a Santo Agostinho ocorre logo no fechamento das Medita-

1 Tal passagem, contida no livro XI, cap. 14, das Confissões, pode ser traduzida como: "Se ninguém me pergunta, sei; porém, se quero explicá-lo a quem me pergunta, então não sei". 
Ções Cartesianas, de 1931, e seu sentido vai na mesma direção da primeira: "Deve-se primeiro perder o mundo pela epoché, para ganhá-lo de novo numa autorreflexão universal. Noli foras ire, disse Agostinho, in te redi, in interiore homine habitat veritas" (Husserl, 2013, p.195).

É digno de atenção que Meditações Cartesianas consiste justamente em uma obra que começa com Descartes e termina com Agostinho. Embora estes dois últimos pensadores tenham colocado o acento no espírito, tomado como realidade indubitável, Agostinho - ao contrário de Descartes - não buscou fazer do cogito um axioma, que serviria de fundamento sobre o qual se deduziria, à moda dos geômetras, a totalidade do conhecimento. De fato, é a tentativa de se fazer do cogito um axioma e não uma região privilegiada a ser descrita, o núcleo da crítica husserliana ao pensador francês. Para Descartes, o cogito seria o ponto de apoio para uma de dedução, para Husserl é o campo de uma descrição. É neste último ponto que encontramos uma certa sintonia, apesar dos séculos, entre Husserl e Agostinho. Este último buscou descrever, em sua vasta obra, com o aparato conceitual de seu tempo, os meandros da alma humana. Ainda que suas descrições se encontrem entremeadas por suas concepções teológicas, devemos lembrar que até mesmo a sua teologia carrega em si um apelo à própria experiência, no caso, à experiência de Deus (Cary, 2000; Rist, 2001). Em função da sensibilidade de Agostinho frente aos dramas da existência, de seu acento no eu individual, no privilégio do papel epistemológico da primeira pessoa, o filósofo espanhol Ortega y Gasset (1971) atribuía a Agostinho o título de ser não só o primeiro grande explorador da consciência humana, mas também o primeiro romântico.

Neste artigo, não iremos nos deter, especificamente, no problema do tempo, mas em outros dois temas, cuja relevância, nos parece, não é menor, sobretudo por razoes históricas. O primeiro tema se concentra na expressão latina "intentio animi" e o segundo remete àquilo que Husserl designou de "reflexão". Esses dois temas, como se verá, encontram-se articulados com uma série de outros temas, como a percepção, a retenção, o ato de lembrar, a sucessão de pensamentos.

Finalmente, é preciso destacar que não pretendemos fazer uma análise exaustiva dos temas aqui abordados, mas apenas fazer algumas indicações que oferecem veredas para futuras pesquisas. A obra de Agostinho usada como corpus de análise é a Sobre a Trindade. Trata-se de uma obra escrita por Agostinho entre os anos de 400 até 416, ou seja, sua escrita se inicia logo após a publicação de Confissões. Os livros de VII a XV consistem em um dos lugares onde Agostinho apresenta suas análises mais detalhadas da vida do espírito.

\section{0 pensamento das realidades sensíveis: a forma impressa no olhar da mente}

Na Trindade, uma das estratégias de Agostinho para examinar o que é o cogito, a faculdade de pensar, é examinando o que pode ser pensado. O ser humano, de acordo com Agostinho, pode pensar em realidades sensíveis e em realidades inteligíveis, embora nos seja mais fácil pensar sobre as primeiras: "Em consequência de nossa condição humana, que nos converte em seres mortais e carnais, lidamos mais fácil e familiarmente com as realidades visíveis (visibilia) do que com as inteligíveis (intellegibilia)" (De Trinit, XI, 1, 1; 2005, p.336²). Para explorarmos o cogito agostiniano, examinemos, inicialmente, como o homem pensa nas realidades sensíveis, para em seguida abordarmos o acesso às realidades inteligíveis.

Para compreendermos como o homem pensa as realidades sensíveis, devemos abordar três processos mentais descritos por Agostinho. Em primeiro lugar, a sensibilidade. Em segundo lugar, a retenção memorativa, ou seja, o arquivamento do material percebido na memória. Em terceiro lugar, $\mathrm{o}$ ato de pensar (cogito) propriamente dito.

No livro XI da Trindade, Agostinho investiga como captamos as realidades exteriores pela percepção, tomando como base para suas análises o sentido da visão. Agostinho justifica a escolha da faculdade da visão argumentando que o que é estruturalmente válido para um dos sentidos será igualmente válido para os demais. São três realidades presentes em toda a visão:

1) Realidade vista (rem quam uidemus), a qual possui uma forma.

2) O sentido da vista (sensus oculorum), que existia antes de o sentido ter percebido o objeto. Para Agostinho, o sentido da vista pode assumir a forma do objeto, isto é, ser informado pelo objeto (De trinit., XI, 2, 5; 2005, p.342). 3) O elemento "copulativo", que vincula o sentido da visão ao objeto exterior. Este elemento é denominado por ele de "atenção da alma” (intentio animi) (De trinit, XI, 2,2; 2006, p.337), outras vezes "vontade" (voluntas) (De trinit., XI, 2, 5; 2005, p.342), outras vezes ainda "atenção da vontade" ou "intenção da vontade" (intentio voluntatis) (De trinit., XV, 3, 5; 2005, 485). É este terceiro elemento que mantém o sentido dirigido ao objeto para ser informado pela sua forma (De trinit., XI, 2, 2; 2005, p.337). A esse respeito, escreve Agostinho:

Assim sendo, recordemos como as referidas três realidades: a figura do objeto visto (species corporis), sua imagem (imago) impressa em nosso sentido, e a vontade da alma (voluntas animi) que aplica o sentido ao objeto sensível e nele mantém a visão -, repito, como essas três realidades, embora sejam de naturezas diferentes, amalgamam-se em certa unidade. ( $D e$ trinit., XI, 2, 5; 2005, p.342)

A visão é, portanto, definida como o sentido informado pelo objeto sensível, pela ação da vontade. O objeto, dotado de forma, exerce uma ação

2 Para facilitar a consulta, usamos ao lado das referências da APA, as referências da patrologia latina de Migne, que é de uso corrente. Abreviamos Confissões por “Conf.”, em seguida o número do livro da obra, do capítulo e do artigo. 
sobre o sentido dos olhos, imprimindo sua forma. Sob este aspecto, o sentido é passivo com relação à forma do objeto (De trinit., XI, 2, 2; 2005, p. 338). Por outro lado, a atenção (intentio), que pertence à mente (mens), será responsável pelo caráter ativo da visão: dentro do horizonte de objetos possíveis a serem vistos, sempre há um no qual a atenção se aplica. Como diz Agostinho, é a atenção da alma "que retém o sentido no objeto percebido e enlaça a ambos" (De trinit., XI, 2, 2; 2005, p. 338). Quando não prestamos atenção no mundo exterior, embora tenhamos os sentidos informados, não "vemos", isto é, não percebemos o objeto no modo da atenção.

Para Agostinho, a visão de um corpo, por ser composta de três elementos, pode ser compreendida como uma espécie de trindade, uma vez que é composta por três elementos distintos que formam uma só visão. Contudo, a trindade da visão é estruturalmente distinta da Trindade divina por não comportar igualdade de substância entre os termos componentes. Dos elementos presentes na visão, o objeto visto pertence ao mundo corporal, ao passo que a intentio pertence à mente, que usa o sentido dos olhos como quem se serve de um instrumento corporal para a captação das formas exteriores que ficam impressas nos olhos: "E embora um corpo sem vida não tenha sensações, a alma, no entanto, unida ao corpo, sente através de um instrumento corporal, instrumento esse chamado de sentido" (De trinit., XI, 2, 2; 2005, p. 338)

Esse esquema para a compreensão da visão trouxe para Agostinho um problema a ser enfrentado: na visão, o que está fora, o que está dentro da alma? Quando vejo algo, tenho a impressão de que vejo algo no espaço, de que vejo algo que está fora de mim. Mas como isso é possível, já que a visão é algo interior à alma? Agostinho responde que, na visão, dois componentes pertencem ao vidente: os sentidos e a atenção (intentio). Entretanto, o objeto real para o qual a visão se dirige está fora:

O primeiro desses três elementos, ou seja, o objeto visível, não pertence à natureza do vivente, dotado de alma, a não ser quando olhamos o nosso próprio corpo. A segunda pertence-lhe de tal modo que se produz no corpo e por meio do corpo também na alma. Com efeito, atua no sentido que não pode operar sem o corpo e sem a alma. Quanto ao terceiro elemento, refere-se tão-somente à alma, porque é a própria vontade (voluntas). (De trinit., XI, 2, $5 ; 2005$, p.342)

É interessante notar que, neste processo, é a atenção da vontade (intentio voluntatis) que vincula o interior ao exterior, pois é ela que fixa o sentido ao objeto exterior. Em tal explicação podemos observar o germe do conceito de intencionalidade fenomenológica, afinal é a atenção da vontade ou intenção da vontade (intentio voluntatis) a responsável pela habilidade da mente captar aquilo que a transcende. Por outro lado, Agostinho observa que a visão do objeto não contém em si o objeto corporal exterior, mas a forma ou a imagem do objeto. O objeto real imprime sua forma no sentido, formando na visão a sua forma.

Há, podemos dizer, uma aporia na teoria da visão agostiniana. Embora Agostinho atribua à intentio $^{3}$ o papel de ligar o exterior ao interior, ele, por outro lado, está preso à concepção de que o objeto impresso na visão não é o objeto exterior. Quando eu vejo, eu vejo o próprio objeto ou eu vejo a forma do objeto estampada no sentido? A teoria agostiniana trabalha com a noção de que vemos o objeto externo apenas de maneira mediata. O que é dado imediatamente é a forma impressa no sentido. Agostinho, de fato, parece estar ciente de tais dificuldades teóricas. Diante delas, ele se vê obrigado a se estender sobre o fato de que a imagem do objeto visto está no vidente. O problema é que aquele que vê não tem a impressão de que vê uma imagem dentro de si. Pelo contrário, tem a impressão de que a visão se estende para o exterior, se alongando até o objeto, como ele próprio comenta em certa passagem: “(...) o olhar estende-se ao que está fora, e alonga-se mesmo até os astros" (De trinit., XIV, 5, 8b). Aparentemente, os olhos são como janelas, uma abertura pela qual vemos as próprias coisas exteriores no espaço. Todavia, Agostinho se contrapõe a essa “atitude natural”. Quem vê não é o sentido da visão, mas alma humana (animus). Assim, há, na teoria de Agostinho, uma certa tensão. Por um lado, a alma, por assim dizer, sai de si mesma, para encontrar o objeto exterior e imprimir a forma deste último no sentido. Por outro lado, a visão está no vidente e, portanto, o que a alma efetivamente vê é a forma ou a imagem do corpo, impressa no sentido.

Agostinho procura defender a tese de que a visão do objeto se dá mediante imagem apoiando-se em vários exemplos (De trinit., XI, 2, 3; 2005, p.339-340). Inicialmente, ele procura examinar o caso de um anel que carimba um pedaço de cera. Neste caso, é fácil diferenciar a forma impressa na cera da forma do próprio anel, a despeito da similaridade das duas. Na alma, afirma Agostinho (De trinit., XI, 2, 3; 2005, p.339), ocorre algo semelhante. Mas, para usarmos um exemplo adequado ao caso da visão exterior, teríamos que imaginar um anel imerso na água em vez de um anel cravado na cera. Enquanto o anel permanece mergulhado na água, ele deixa nela sua forma, mas tão logo é retirado do líquido, sua forma deixa de estar no líquido. Analogamente, assim que o objeto deixa o campo visual, ele para de imprimir sua forma no sentido.

O mesmo acontece em relação à água, que guarda o vestígio do corpo, enquanto esse nela permanece. Retirando tal corpo, todo vestígio desaparece, ficando somente a água que existia antes de receber a forma daquele corpo. Por isso, não podemos dizer que é o objeto visível que gera a visão. Gera, no entanto, essa forma que é como uma semelhança sua, que atua no sentido da vista ao termos a sensação. (De trinit., XI, 2, 3; 2005, p.339).

$3 \quad$ A intentio também joga um papel central na imaginação. Para uma discussão mais detalhada deste tópico, ver O'Daly (1987). 
Como a forma do objeto deixa de informar os sentidos assim que sai do campo de visão, o homem tende a confundir a forma do próprio objeto com a forma do objeto impressa no sentido. No entanto, afirma Agostinho, são duas formas que estão em jogo. A forma do objeto pré-existe no próprio objeto e é a partir dela que a forma se imprime no sentido, formando a visão. Um segundo exemplo empregado por Agostinho para defender sua teoria encontra-se no caso de um homem que olha para um objeto luminoso e, em seguida, fecha os olhos. Logo que fecha os olhos, o homem verá os borrões de tal objeto, os quais são como rastros momentâneos da forma do objeto no sentido.

O que pode causar confusão, diz Agostinho, é que a diferença entre a forma do próprio corpo e a forma impressa em no sentido não pode ser constatada, pelo vidente, com os seus próprios olhos, dada a estreita união entre ambas: "E por isso difícil convencer as pessoas de pouca capacidade, que se forma no nosso sentido uma imagem do objeto visível, enquanto o vemos, e que essa forma ou imagem é a visão.” (De trinit., XI, 2, 3; 2005, p.339).

A ideia de que exista uma forma impressa no sentido pressupõe a existência de uma forma exterior, a qual é responsável por afetar os sentidos, pela ação da vontade. Mas como é possível que o homem se certifique de que visão do objeto corresponda ao objeto exterior? Afinal, todo acesso que o homem tem do mundo exterior é pelos sentidos, e estes são interiores. Agostinho, com efeito, percebe aí o risco do solipsismo, afinal, tudo que a alma humana possui do mundo exterior corpóreo são imagens que estão nela própria. O que há, na mente, são imagens interiores de um "suposto" mundo exterior. Agostinho procura sair desse dilema recorrendo àquilo que poderíamos denominar "teoria das formas".

A forma é o denominador comum entre o corpo exterior e a imagem interior. E é a intentio voluntatis que faz a ponte entre a forma exterior, do próprio objeto, e a forma interior, intrínseca à visão. É certo que ao introduzir a noção de forma ele não soluciona todos os problemas de sua teoria. Pois se é verdade que a imagem interior possui uma forma, como certificar que essa forma corresponde à forma do objeto exterior. Evidentemente, não é a própria visão que garante a existência da forma exterior. Agostinho busca resolver esta questão afirmando que é pela racionalidade, e não pela visão, que sabemos que existem corpos exteriores dotados de forma. Trata-se de uma hipótese que não pode ser provada a partir da experiência sensível. Não é pelo sentido que distinguimos a forma do próprio corpo da forma impressa no sentido, mas sim pelo juízo da razão (iudice ratione): "Ora, sendo essas três realidades de substâncias diferentes, amalgamam-se, contudo, em uma unidade tal que as duas primeiras, ou seja, a figura do objeto que se vê e sua imagem no sentido, denominada visão, podem apenas ser distinguidas pela intervenção da razão”. (De trinit., XI, 2, 5; 2005, p.342). Neste sentido, não espanta que Agostinho busque elucidar o problema da relação entre a visão e o mundo exterior recorrendo a uma teoria das formas, a qual, em vários aspectos, lembra a teoria aristotélica. Mas há diferenças.
Em De anima, Aristóteles (2006) afirma que os objetos imprimem suas formas na alma. Daí resultaria que os objetos exercem ação na alma. Segundo Gilson (2006), Agostinho não aceita essa concepção, pois, para ele, as realidades inferiores não podem exercer ação sobre as realidades superiores. O dilema pode ser posto nas seguintes palavras: a visão é uma ação ou uma paixão da alma? Em Aristóteles, a visão é uma paixão. Mas a teoria de Agostinho vai além, porque os sentidos, por si só, não determinam e afetam o animus. A afecção dos sentidos não é suficiente para que haja a visão. Para tanto, é necessário, como vimos, a intenção da alma (intentio animi), elemento ativo, copulativo, puramente espiritual, que possibilita o acesso da alma aos entes corporais.

\section{A retenção e o pensamento das realidades sensíveis}

Para Agostinho, a retenção memorativa se constitui como um processo análogo ao de ver o objeto (De trinit., XI, 3,6; 2005, p.342-344). Do mesmo modo como o objeto sensível imprime sua forma no sentido da visão, a forma presente na visão imprime sua forma na memória. Neste processo, a vontade também desempenha um papel central. Também neste caso, ela é, para Agostinho, o elemento copulador. Em termos plásticos, podemos dizer que é a vontade que agarra a forma do objeto na visão e a carimba na cera da memória. Deste modo, as realidades exteriores entram, em imagem, pela ação da vontade, nos vastos palácios da memória.

Uma vez que uma imagem esteja retida na memória, torna-se possível ao ser humano pensar no objeto. O pensamento ocorre quando a forma do objeto corpóreo, armazenada na memória, imprime sua forma no olhar da mente, pela ação da vontade, que une ambos. Também aqui, o ato de pensar funciona de maneira análoga à percepção. No ato de pensar, a imagem do objeto que está na memória informa o olhar do espírito, também pela ação da vontade. Ou seja, pensar é ver com o olhar do espírito determinados conteúdos da memória.

(...) desaparecida a figura corporal que atuava sobre o sentido corporal, permanece na memória uma imagem desse objeto, imagem essa que pode levar a vontade a voltar-se novamente a ela com o olhar da alma. A informação passa-se assim ao interior, tal como do exterior o sentido era informado mediante o objeto sensível. Produz-se desse modo uma nova trindade produzida pela memória, pela visão interna e pela vontade que a ambas enlaça. Quando essas três coisas estão reunidas em um só todo, essa reunião é dita ser o pensamento - palavras cuja raiz lembra essa união. (De trinit., XI, 3,$6 ; 2005$, p.343)

Sumarizando, podemos falar que a forma do objeto no ato de pensar encontra-se "distanciada", quanto à sua geração, da forma original, pertencente ao próprio objeto. O que ocorre é que uma forma 
vai gerando a outra, devido à ação da vontade: a forma do objeto gera a forma nos sentidos, que gera a forma na memória, que, por vez, gera a forma no olhar da mente quando ocorre o ato de pensar (De Trinit, XI, 9,16).

\section{Inteligência das realidades inteligíveis}

Para Agostinho, a mente possui três faculdades essenciais e inseparáveis: o intelecto, a memória e a vontade. Em todos os atos mentais, estas três faculdades estão, de algum modo, envolvidas. $\mathrm{Na}$ seção anterior, vimos que o cogito ocorre quando um conteúdo da memória é posto, pela vontade, diante do olhar da mente. O conteúdo posto diante do espírito não é simplesmente contemplado passivamente, mas também entendido pelo olhar da mente. E, para Agostinho, aquilo que está diante do olhar da mente nem sempre tem sua origem na sensibilidade. É o caso, por exemplo, das verdades matemáticas. Para esclarecermos como a mente tem acesso às realidades inteligíveis e qual a natureza delas, devemos examinar a faculdade do intelecto.

$\mathrm{O}$ intelecto (intellectus) possibilita o acesso às realidades inteligíveis. O próprio intelecto é uma realidade inteligível (Trinit, XI, 1, 1) e, nesta medida, o intelecto possui acesso a si próprio. As realidades inteligíveis são de dois tipos: variáveis e invariáveis. As regras e os objetos matemáticos, por exemplo, são inteligíveis e invariáveis. O número três é sempre igual a si próprio, assim como a soma de $2+2$ sempre dará quatro. A fé, ao contrário, seria um exemplo de uma realidade inteligível, embora variável. Não podemos ver a fé com os sentidos, mas com o intelecto. Embora inteligível, a fé pode tanto nascer quanto se extinguir do coração.

A distinção entre realidades sensíveis e realidades inteligíveis não diz respeito a dois mundos separados por um abismo. Também as realidades sensíveis possuem elementos inteligíveis, apreensíveis pelo intelecto. Sem os sentidos, não saberíamos o que é o verão nem o inverno. Contudo, a ordem segundo a qual as estações do ano variam não é uma realidade sensível. Embora alguns invernos sejam mais rigorosos, outros menos, há uma espécie de proporção entre as durações do verão e do inverno. E esta proporção pode ser apreendida pela visão intelectual:

Contudo, é a uma função mais alta da inteligência (razão) que pertence a possibilidade de fazer juízo a respeito dessas realidades corporais, segundo razões incorpóreas e eternas. Essas razões, se não estivessem acima da mente humana não seriam imutáveis. Entretanto, se elas não tivessem nenhuma ligação com nosso ser, que lhes é submisso, não poderíamos emitir juízo algum a respeito daquelas realidades corporais. Ora, fazemos juízos sobre tais realidades baseados na razão de suas dimensões e figuras, e cuja razão nossa mente (mens) reconhece como imutável. (De trinit., XII, 2, 2; 2005, p.367).
Para Agostinho, o acesso às razões e as formas ideais são explicadas em integração com o seu pensamento teológico. Deus criou os entes no mundo, cada qual com uma forma. Tais formas subsistem na mente divina. Deus é onipresente e está no espírito de cada ser humano. Daí que é possível a todo ser humano, dentro das limitações humanas, ver, dentro de si, certas ideias perfeitas, como as noções matemáticas.

\section{Crítica ao pensamento de Platão}

É bem possível que as concepções de Agostinho sobre as realidades inteligíveis sejam inspiradas pelo Neoplatonismo de Plotino, e, portanto, tenham suas raízes no pensamento de Platão (Reale \& Antiseri, 2003). O próprio Agostinho estava ciente da proximidade de seu pensamento com o do mestre grego. No livro XII da Trindade, ele alude ao diálogo Menon, de Platão, no qual um jovem escravo, instado pela maiêutica socrática, chega "por si só”, ao teorema de Pitágoras: "Conta ele (Platão) que certo jovem, interrogado não sei sobre que assunto de geometria, respondeu como se tivesse invejável competência nessa disciplina. Tendo-se feito perguntas sucessivas e artificiosas, via ele o que devia ver e dizia o que via” (De trinit.,XII, 15, 24; 2005 , p.390).

Agostinho assume que é possível que alguém, questionado com arte, encontre dentro de si as respostas às perguntas a respeito de geometria ou de matemática. Mas tal método de conhecimento é, para Agostinho, limitado. E é essa limitação que nos proíbe de aproximarmos demais o pensamento de Agostinho do de Platão. Agostinho, de fato, faz questão de marcar alguns pontos nos quais ele se distancia do mestre grego. No livro XII da Trindade, Agostinho afirma que Platão, para explicar o acesso do homem aos inteligíveis, recorreu à noção de que “(...) as almas humanas já viviam neste mundo, inclusive antes do nascimento dos corpos". (De Trinit, XII, 15, 24; 2005, p.390). Contra tal argumento, Agostinho objeta que o fato de alguém encontrar dentro de si algumas verdades não prova a concepção platônica do conhecimento como alétheia. O exemplo citado por Platão simplesmente prova que o homem é capaz de encontrar dentro de si determinadas realidades inteligíveis, como as geométricas, mas não toda e qualquer realidade inteligível. Platão havia cometido uma generalização indevida. Ele estava certo ao afirmar que a mente encontra em si algumas verdades inteligíveis. Mas se todo espírito é capaz de chegar, com o uso da maiêutica, ao teorema de Pitágoras, seria porque todos foram geômetras em vidas anteriores? Agostinho rejeita essa hipótese:

Ora, se fossem apenas recordações de conhecimentos anteriores, nem todos, nem mesmo uma maioria que fosse, poderia se lembrar ao serem interrogados sobre esse determinado assunto. Pois nem todos devem ter sido geômetras na vida anterior, visto que esses são tão poucos entre os homens que dificilmente se 
encontra alguém. Assim, é preferível acreditar que a natureza da alma intelectiva foi criada de tal modo que, aplicada ao inteligível segundo sua natureza, e tendo assim disposto o Criador, possa ver esses conhecimentos em certa luz incorpórea de sua própria natureza. Assim acontece com o olho do corpo que vê os objetos que o cercam na luz natural, pois pode-se acomodar a essa luz, já que para ela foi feito. (De trinit., XII, 15, 24; 2005, p.390).

A resposta de Agostinho para o problema do acesso aos inteligíveis é que as verdades estão dentro do homem porque Deus está dentro e acima do espírito. Uma vez que Deus encontra-se dentro de cada espírito, torna-se possível a este participar, em determinada medida, da sabedoria de Deus. A possibilidade de acesso a determinadas realidades inteligíveis não significa conhecimento prévio do mundo sensível. Quem nunca viu um elefante nem ouviu falar de tal animal não poderá encontrar, dentro de si, a ideia do elefante. A única maneira de se obter a ideia de um elefante é pela experiência sensível do animal. Em suma, para Agostinho, o conhecimento das realidades sensíveis tem sua fonte na percepção.

\section{Sensibilidade, a reflexão e o erro}

No capítulo 12 do livro XV da Trindade, Agostinho assume que os neoacadêmicos possuem certa razão em afirmarem que o conhecimento das coisas sensíveis está sujeito ao erro. Muitas vezes o homem se deixa levar por "falsas aparências", como um remo parece quebrado quando é parcialmente submerso na água. Neste caso, a aparência não corresponde à realidade do objeto, havendo uma distinção entre o que a coisa é e seu modo de aparecer. Mas a questão é que essa distinção entre ser e aparecer não é válida para todos os casos. No que concerne às realidades interiores, essa distinção não se sustenta. Para Agostinho, homem não pode estar enganado a respeito do fato de que ele vive, "Intima scientia est qua nos vivere scimus." (De trinit., XV, 12, 21b; 2005, p.510). Tal verdade não é abalada por nenhum tipo de objeção. Não podemos, contra ela, objetar que estejamos dormindo e sonhando, pois quem sonha vive. E do mesmo modo, de nada vale a objeção: "Deliras, está enganado", pois quem delira vive. Como expõe Agostinho:

Repito que, excetuadas as coisas que chegam a nós pelos sentidos, quantas outras restam que conhecemos com certeza, como, por exemplo, o fato de sabermos que estamos vivos. Neste pormenor, não tememos absolutamente ser enganados por falsa verossimilhança, pois aquele mesmo que se engana, vive, e também tem certeza disso (De trinit., XV, 12, 21b; 2005, p.510).

Há uma importante distinção entre o conhecimento das realidades sensíveis e das realidades inteligíveis. O conhecimento sensível consiste em uma imagem do objeto sensível, o conhecimento inteligível consiste na presença, no espírito, do próprio objeto inteligível. Temos, na memória, não um cavalo, mas a imagem do cavalo. Contudo, não temos na memória uma mera imagem do número, mas o próprio número. Por outro lado, todas as pessoas que pensam em um número, pensam no mesmo número, pois o número é uma ideia de Deus e Deus é onipresente.

Essa distinção entre duas formas de conhecimento tem, como contraparte, duas formas de acesso epistêmico ao objeto. O conhecimento do mundo corporal é mediado pela imagem do objeto. O conhecimento das coisas inteligíveis não. A mente percebe os próprios inteligíveis em si mesma. Uma das consequências desta distinção é que o problema do erro e do engano não pode ser posto da mesma maneira para as duas espécies de conhecimento. O engano surge quando a coisa se mostra tal como ela não é. Por isso, o engano só é possível com relação aos entes cujo ser não coincide com o seu aparecer. Desde então, o problema do engano não se apresenta no caso do conhecimento das realidades interiores. Ao defender tal posição, Agostinho se distancia dos neoacadêmicos, os quais consideravam que conhecimento sensível era o único tipo possível de conhecimento. Ao partir de tais posições, Agostinho começa a observar que os conhecimentos que a mente possui de si própria, obtidos por reflexão, possuem um estatuto superior ao conhecimento do mundo exterior.

\section{A dinâmica do cogito}

Para Agostinho, o ato de cogitar abarca o ato de recordar, de imaginar, de planejar, de ter expectativa. Podemos dizer que cada um desses atos são tipos de cogito. O denominador comum destes atos, como vimos, é que, neles, o olhar da mente encontra-se informado por um conteúdo da memória, pela ação da vontade (De trinit., XI, 3,6; 2005, p.343). A consequência de tal definição é que não podemos pensar naquilo que não tem sua matéria prima na memória. A memória, por outro lado, não contém apenas aquilo que entrou pelos sentidos. Deus e as ideias de Deus habitam a memória. E, ademais, a memória armazena as próprias atividades do próprio espírito, o qual é uma realidade inteligível.

A explicitação do ato de pensar exige a distinção entre ter algo no espírito e ter algo diante do olhar do espírito. Nem tudo o que está no espírito está diante do olhar do espírito ${ }^{4}$. A distinção evidencia uma das limitações da mente humana. Ela não poder vislumbrar, em um único instante temporal, tudo quanto há na memória. Essa limitação está diretamente ligada à temporalidade: para que tenhamos o olhar da mente informado por uma coisa, é necessário deixar de pensar em outra. Em outros termos, pensamos em algo porque este algo é

4 Não é difícil perceber que essa distinção revela algo muito próximo do que hoje se entende por consciência enquanto dados imediatos ao eu. E de inconsciente ou pré-consciente, enquanto dados que podem vir a se tornar imediatos. Basta considerar que aquilo que está na memória é, na medida em que não está informando o olhar da mente, é "inconsciente" ou "pré-consciente". 
posto, pela vontade, diante do olhar da mente. Mas no momento em que a vontade "põe" um conteúdo, ela deve "retirar" outro conteúdo diante do olhar da mente. Trata-se de um trabalho incessante da vontade de pôr e tirar conteúdos diante do olhar da mente. É justamente em virtude desse movimento contínuo da vontade que ocorre a sucessão de $\mathrm{CO}$ gitatones:

Mas como a visão da alma humana não pode abranger com um só olhar tudo o que está retido na memória, as trindades do pensamento se revezam, aproximando-se e retirando-se, alternadamente. Isso faz resultar trindades numerosíssimas, contudo não em número infinito, pois não superam o número das imagens conservadas na memória. (De trinit., XI, 8, 12b; 2005, p.355).

Poderíamos traçar um paralelo entre a sucessão de cogitationes e o que atualmente se costuma denominar de fluxo de pensamento. Contudo, o termo "fluxo de pensamento" pode dar uma impressão equivocada. A ideia de fluxo pode transmitir a noção de continuidade fluida. Para Agostinho, ao contrário, o que há são sucessões discretas de trindades do pensamento, "cedendo ac succedendo trinitates cogitationum” (De trinit., XI, 8, 12b; 2005, p.355).

Há, como vimos, um estreito nexo entre a vontade e o tempo presente. O que é presente ao espírito é aquilo que é posto pela vontade diante do olhar do espírito. O cogito, por ser o fruto da reunião de três elementos formando uma trindade, não implica necessariamente a sucessão de trindades. Podemos imaginar uma situação hipotética em que a vontade permanece fixa em um único objeto, mantendo-o presente diante do olhar da mente. Neste caso, teríamos, por assim dizer, um único pensamento, que não passaria para que outro pensamento viesse. A princípio, poderíamos nos manter neste estado contemplativo por toda eternidade.

O que podemos apreender das descrições acima realizadas por Agostinho é que a vontade é um fator decisivo para explicar não apenas a estrutura interna de cada um dos pensamentos, mas a sucessão dos pensamentos. Com isso, Agostinho opera com um conceito alargado de vontade. A vontade não é apenas uma classe de atos que ocorre ocasionalmente, quando queremos algo. A vontade está presente em todos os atos e na conexão entre os atos do cogito. Por outro lado, afirmar que a vontade é um elemento central para a compreensão do curso do pensamento não implica em afirmar que a irracionalidade domina o pensamento. A vontade, em Agostinho, não é cega, pois ela é um momento de um todo espiritual, ou seja, não há vontade sem intelecto e memória. Assim, a direção do fluxo pode ser racional ou irracional, dependendo da vontade que está em jogo. Essa expansão do conceito de vontade, como elemento integrante da estrutura dinâmica do espírito, antecipa, em vários aspectos, a concepção husserliana de motivação. Para Husserl, a motivação é a lei fundamental do espírito. O nexo entre as vivências intencionais não pode ser expli- citado por um modelo causal-natural, pois trata-se de um nexo causal-motivacional. Como Husserl afirma:

Todos os modos de comportamento espiritual são conectados "causalmente" através de relações motivacionais (Beziehungen der Motivation); por exemplo: eu suponho que A seja, porque sei que B, C... são. Sei que é fugido um leão, sei que o leão é um animal feroz, e portanto tenho medo de sair pela estrada. O servidor encontra seu chefe, e posto que o reconhece, o saúda com deferência. Anotamos sobre a nossa agenda o que devemos fazer amanhã: a consciência de um propósito, conectada com a consciência da nossa tendência ao esquecimento, motiva a nossa anotação. Em todos estes atos está contido o porquê da motivação (1952, p.230).

A fenomenóloga Edith Stein procura expressar o conceito de motivação através de uma fórmula que lembra ainda mais a concepção de Agostinho, o qual atribui à vontade o papel, dentre outros, de estabelecer o elo entre as cogitationes:

A motivação é a ligação que conecta os atos entre si, não se trata de uma simples união, como aquela das fases que transcorrem uma em seguida da outra no fluxo de vivências, ou de uma ligação associativa de vivências; trata-se antes de uma vivência que provém de outra, de uma vivência que se realiza sobre a base de outra, por querer de outra. (Stein, 1922/2010, p. 36, os grifos são meus).

\section{Atenção e desatenção}

Vimos que a faculdade que liga o conteúdo da memória ao olhar da mente é a vontade. Agostinho, por vezes, designa o elemento copulador pela expressão latina "intentio voluntatis". Mas o que devemos entender por tal expressão? Em primeiro lugar, devemos observar que o termo latino "intentio" possui um o sentido mais amplo do que o português "intenção". Intenção, no português, é geralmente empregado para designar um propósito. Em seu sentido corriqueiro, se uma ação é feita propositadamente, ela é feita intencionalmente. Contudo, esse sentido é apenas um dos sentidos da expressão latina. Em seu sentido mais amplo, intentio significa "tender em direção a algo". Dada sua amplitude, o termo intentio pode ser traduzido, dependendo da ocasião, por "atenção", "intenção" (no sentido de propósito), e mesmo como "intender". Assim, fica claro que Agostinho, ao designar o elemento copulador pela expressão intentio voluntatis enfatiza o estreito vínculo entre a atenção e a vontade. $\mathrm{Ou}$ seja, prestamos atenção naquilo para onde nos dirige nossa vontade.

Em vários momentos de sua obra, Agostinho contrapõe as expressões latinas "intentio" e "distentio”. Com esse par, Agostinho busca elucidar vários fenômenos, os quais estão vinculados entre si. Em 
primeiro lugar, o par conceitual é empregado para articular experiência subjetiva do tempo, uma vez que o tempo é, segundo a célebre fórmula encontrada nas Confissões, uma “distentio animi”. Em segundo lugar, Agostinho usa o mesmo par conceitual para elucidar como ocorre os desvios da vontade, quando deixamos, por distração, de seguir uma determinada meta. Neste último sentido, a "intentio" poderia ser traduzido por atenção, e "distentio" por distração.

A relação entre intentio e distentio é fundamental para entendermos o problema concernente à dinâmica do cogito. A distração não é a anulação da atenção, um mero oposto de atenção. Distrair é deixar de prestar atenção em algo para prestar atenção em outro algo. A distração diz respeito à mobilidade do foco de atenção.

Para Agostinho, a distração é fonte de vários desvios éticos, já que ela pode se apresentar como um desvio da vontade. E há, no homem, uma forte tendência à distração. Uma das formas pela qual a distração (distentio) se manifesta é como um desvio despercebido de um objetivo previamente estabelecido por um ato da vontade. Em outros termos, a desatenção é resultante de uma vontade desviante que, por assim dizer, rouba a atenção. Agostinho cita como exemplo o sujeito que, ao rezar, pensa em outro assunto.

O drama da desatenção encontra-se no fato de que entre a decisão de fazer algo e sua realização há um intervalo temporal. Para que uma decisão alcance o seu fim, é preciso que a vontade não se perca nesse ínterim. Na maior parte das vezes, a decisão se separa de sua realização por incontáveis circunstâncias, as quais demandam a atenção. Muitas destas circunstâncias carregam em si atrativos, que se apresentam como "tentações". Uma tentação pode ser entendida como aquilo que pode desviar a pessoa da vontade reta.

A atenção possui duas direções possíveis, uma centrífuga e uma centrípeta. Pode dirigir-se ao mundo presente aos sentidos ou voltar-se para dentro de si. Ainda que a atenção esteja voltada para dentro, o mundo exterior não deixa de atuar nos sentidos. Mas, quando a atenção está voltada para dentro, a atuação do mundo exterior sobre os sentidos é, por assim dizer, invalidada, pois para que a forma do objeto no sentido seja impressa na memória é preciso, como vimos, a ação da vontade. Se a atenção está voltada para dentro, a vontade está ocupada com o próprio espírito ou com os conteúdos da memória. Quando isso ocorre, nós vemos, mas não retemos no espírito o que vemos. Para retermos a forma de um objeto sensível no espírito, é preciso que prestemos atenção ao "mundo dos sentidos". Agostinho ilustra esse fenômeno com o caso de alguém que está lendo um texto e subitamente se dá conta de que apenas passava os olhos pelas páginas sem assimilar nada (De trinit., XI, 8, 15; 2005, p.358). Algo semelhante ocorre quando alguém nos dirige a palavra, mas estamos prestando atenção em outra coisa:

Em relação à memória, a vontade desvia-a dos sentidos fazendo-a atenta a outras coisas e não lhe permitindo fixar-se nos objetos presentes no momento. Constata-se isso facilmente, por exemplo, quando parecemos não escutar quem nos dirige a palavra, por estarmos com o pensamento ocupado com outra coisa. Mas tal não é verdade, pois escutamos, e se não recordamos, é porque a atenção, que fixa as impressões em nossa memória, estava desviada por um movimento diferente da vontade perante as palavras que apenas resvalaram pelo sentido da audição. (De trinit., XI, 8, 15; 2005, p.358).

Em outro exemplo, Agostinho comenta a respeito de um caminhante que vai andando tão absorto em seus pensamentos, que, quando "cai em si”, não sabe sequer o percurso que fez. O caminhante via o caminho, dado que não trombava em nada. Mas, por outro lado, não via o caminho, posto que sua atenção se dirigia a outra coisa. Ao observar esse estranho fenômeno, Agostinho coloca-se a seguinte questão. Por que aquele que caminhava, quando "cai em si”, não consegue lembrar-se por onde andou? Agostinho oferece a seguinte explicação: quem se encontra imerso em pensamentos está requisitando sua memória e sua vontade. Enquanto está pensando, a vontade está ocupada na atividade de trazer os conteúdos da memória para diante do olhar da mente. Por isso, a vontade não poderia estar exercendo com zelo a função copulativa de imprimir as imagens dadas aos sentidos na memória, aí as retendo. A experiência do pensar implica uma espécie de abstenção do mundo imediato das presenças corporais. Inversamente, aquele que tem a atenção inteiramente voltada para o mundo circundante, não está pensando: “(...) querer desviar o olhar da alma humana (animi aciem) de um conteúdo da memória é o mesmo que não pensar". (De trinit., XI, 8, 15; 2005, p.359). E como se o que existisse para a mente, em um dado momento, fosse aquilo que se encontra diante do olhar da mente. Por isso, não raro, ocorre do espírito "esquecer" de si mesmo e dos objetivos que outrora se determinou a realizar.

\section{Distinção entre pensar-se e conhecer-se}

No livro XIV da Trindade, Agostinho procura demonstrar a seguinte tese: "Não há nada que a mente (mens) conheça tão bem como aquilo que lhe está presente; e nada lhe é mais presente do que ela, a si mesma” (De trinit., XIV, 4, 7; 2005, p.446). Essa tese, aparentemente simples, esconde uma grande complexidade e suscita uma série de questões. Se a mente é capaz de observar-se e conhecer a si, por que tantos filósofos ilustres erraram ao dizer que a mente era átomos, fogo, ar, uma estrutura ou uma matéria sutil? Como é possível que a mente conheça a si com certeza absoluta e, ao mesmo tempo, creia ser algo que ela não é?

Para discutir tais problemas, Agostinho parte do exemplo de uma criancinha que aprendeu as primeiras palavras e nem sequer sabe o significado dos termos "mente", "espírito" e outros semelhantes. 
Seria correto dizer que a mente de uma criancinha conhece a si mesma, apenas porque está presente a si mesma? O mesmo problema se coloca para uma pessoa nascida em uma cultura rudimentar, na qual não haja um termo capaz de designar a mente. Seria correto afirmar que este indivíduo tem conhecimento de sua própria mente? Tais questões pedem esclarecimentos. Segundo Agostinho, o primeiro ponto a ser fixado é que ninguém negaria que tanto a mente de uma criança, quanto a de um bárbaro, estão presentes a si mesmas. Mas poderíamos deduzir daí que, por estar presente a si mesma, a mente necessariamente se conhece?

Agostinho busca esclarecer esse problema pela distinção entre "conhecer a si" e "pensar em si”. Lembremos que a condição de todo pensar é que o conteúdo pensado esteja diante do olhar da mente. O homem só pode ter o olhar da mente informado por algo se sua atenção estiver aplicada a esse algo. Vimos que a atenção pode se voltar tanto para o interior quanto para o exterior. Na criança, a atenção é basicamente projetada ao exterior: "A alma da criança como que se fecha em sua atenção de tal modo que somente aborrece ou deseja o que a ofende ou atrai fisicamente, com vivo impulso" (De trinit., XIV, 4, 6; 2005, p.446). Os objetos sensíveis possuem um poder imenso de atrair as crianças. Basta observar o quanto elas são atraídas pela luz. Se alguém "colocar à noite uma luz no quarto onde uma criança está deitada, e em um ângulo onde esse pequeno possa torcer o olhar, ainda que sem poder virar o pescoço, seus olhos não se desviarão desse clarão" (De trinit., XIV, 4, 6; 2005, p.446).

Analisando a mente infantil, Agostinho estabelece uma distinção sutil entre pensar em si e o conhecer a si. A mente da criança não pensa em si, pois sua atenção está constantemente voltada para o exterior. Como se não bastasse, é impossível adverti-la para que o faça, já que ela não entende os signos linguísticos necessários para tal. Assim, a criança:

(...) não se pensa em seu interior e nem podemos aconselhá-la que o faça, porque ainda não conhece os sinais de quem a adverte. Ora, entre esses sinais têm primazia as palavras, que ela desconhece totalmente, aliás, como a tudo o mais. Já demonstramos naquele mesmo livro que uma coisa é não se conhecer a si mesmo, outra coisa é não pensar em si mesmo. (De trinit., XIV, 5, 7; 2005, p.446).

O fato de as crianças não dirigirem a atenção ao interior não implica que elas não se conheçam (nosse). Com isso, Agostinho acaba por distinguir duas espécies de conhecimento: (1) um conhecimento que temos, mas que não sabemos, explicitamente, que temos, pois nele nunca pensamos, e (2) um conhecimento temos e que sabemos que temos, na medida em que o olhar da mente já se dirigiu e pode se dirigir, ao seu bel prazer, para ele. Agostinho argumenta que, nos dois casos, a mente conhece a si mesma porque ela tem memória de si. Mas o que significa a mente ter memória de si?

\section{A memória de si}

Nas Confissões, Agostinho argumenta que tudo aquilo que esteve presente na própria mente pode, caso não caia no esquecimento, ser retido na memória. Ora, a mente está sempre presente a si mesma e, nesta medida, ela retém a si mesma. Se vemos algo, podemos, momentos depois, não apenas recordar deste algo, mas também da própria percepção que tivemos deste algo. Analogamente, se queremos algo, podemos, instantes depois, lembrar-nos de nossa própria vontade. Os atos que a mente executa a marcam, permanecendo na memória. E, enquanto não forem sepultados pelo esquecimento, tais atos podem ser lembrados. Sem a memória de seus próprios atos, a mente não poderia nem se conhecer nem se pensar. A memória de si é condição necessária para que a mente seja uma mente.

Apesar de Agostinho não se expressar desta forma, é possível dizer que o conhecimento que a mente tem de si é análogo ao que a fenomenologia designa como conhecimento pré-reflexivo e pré-predicativo. Aquilo que Agostinho designa como pensar em si é análogo ao que a fenomenologia husserliana designa como reflexão. Essa distinção é bem apresentada por Dan Zahavi, quando escreve:

Embora eu não possa estar inconsciente de minha experiência presente, eu posso muito bem ignorá-la em favor de seu objeto, e esta é claramente a atitude natural. Em minha vida cotidiana eu estou absorvido e preocupado com projetos e objetos do mundo. Assim, a autoconsciência pré-reflexiva é definitivamente não idêntica com a total autocompreensão, mas pode ao invés estar ligada a uma precompreensão que permite pela subsequente reflexão e tematização. (Zahavi,1999, p.206).

A mente conhece todos os seus atos pré-reflexivamente e poder voltar-se reflexivamente e atentivamente a estes mesmos atos, por meio de atos reflexivos, de modo a explicitá-los. Vejamos agora o que Agostinho fala deste mesmo tema: "De tudo isso, basta-nos ter certeza de que, quando o ser humano puder pensar sobre a natureza de sua alma e encontrar a verdade, não a encontrará em outro lugar, a não ser em si mesmo. Encontrará, porém, não o que ignorava, mas aquilo em que não pensava" (De trinit., XIV, 5, 8a; 2005, p.447).

De acordo com Agostinho, na medida em que somos capazes de, por meio de uma atenção dirigida para a interioridade, saber que sabemos algo, nós sabemos o que é a mente. Ou seja, é impossível saber que possuímos um conhecimento sem conhecer a própria mente. Afinal, esta é a portadora e o meio de obtenção de todo conhecimento: "Pois, o que sabemos nós, se não sabemos o que é a nossa mente? Visto que tudo o que sabemos, só podemos conhecê-lo por meio de nossa mente?" (De trinit. XIV, 5, 8a; 2005, p.447).

O pensar em si (cogito) e o conhecimento de si (nosse) possuem modos distintos de ser no que se refere à sua dimensão temporal. $\mathrm{O}$ ato de pensar em 
si é um evento que possui uma duração temporal, inicia-se no momento em que a vontade coloca a própria mente diante de seu olhar e termina quando a vontade coloca outro conteúdo diante do olhar da mente. Já o conhecimento, por seu turno, é algo permanente, pois não deixa de existir quando não é pensado. O pensamento é um ato da consciência que possui um conteúdo. O conhecimento, por sua vez, tem algumas características básicas:

1) O conhecimento está numa mente e, em particular, na memória.

2) O conhecimento é conhecimento de algo.

3) O conhecimento tem sua origem no algo do qual é conhecimento.

4) Ao ter experiência de algo, esse algo encontra-se presente na mente, seja em imagem, seja ele próprio.

5) O conhecimento pode vir a ser pensado ou não.

\section{Conclusão}

Ao longo deste artigo, pudemos encontrar alguns pontos de contato entre as descrições da mente realizadas por Agostinho e as descrições fenomenológicas, em particular, as husserliana.

Inicialmente, vimos que o conceito agostiniano de intentio guarda várias semelhanças com o conceito atual de intencionalidade, de tal modo que podemos dizer que Agostinho oferece, do ponto de vista histórico, um considerável impulso ao empreendimento de se descrever a subjetividade. No que concerne à sua teoria da percepção, merece destaque o fato de que, para ele, ela não se limita a ter sensações. A percepção não é, como posteriormente seria para os empiristas inglês, uma coleção de sensações, a uma mera impressão, como se a mente fosse algo passivo. Para Agostinho, os sentidos, sem a atenção da vontade (intentio voluntatis), não constitui a visão. Ainda que Agostinho tenha notado que a percepção não consiste em um fenômeno puramente passivo, o papel da atenção não é, entretanto, cristalino. Por um lado, a intentio faz a cópula entre o objeto exterior visto e o sentido visual, e, nesta medida, ela é responsável pela abertura da mente ao transcendente. Mas, por outro lado, Agostinho opera com uma teoria das formas, de tal sorte que o objeto visto, por vezes, é tido como uma imagem do objeto e não como o próprio objeto. Ainda que haja essa tensão, sua teoria abriu as portas para uma investigação mais minuciosa da percepção, colocando problemas que iriam tirar o sono de futuras gerações de pensadores.

De igual importância é a vinculação entre o conceito de atenção e o de vontade e, junto a isso, um alargamento do conceito de vontade. Toda atividade da mente pressupõe a atenção e a vontade. A intentio voluntatis é responsável, a cada momento, por aplicar a mente a esse ou aquele objeto temático. Neste sentido, há um estrito laço entre a vontade e a própria temporalidade. É a vontade a responsável pela mobilidade da consciência, pelo movimento constante do foco de atenção. E aquilo que é presente ao eu é aquilo para onde a vontade se aplica. A temporalidade da mente se explica, como Agostinho expõe, nas Confissões, no jogo entre intentio e distentio.

É também pela noção de intentio que Agostinho explica a diferença entre pensar em si e conhecer a si. A mente, inclusive das crianças, sempre se conhece de maneira implícita, não conceitual. Mas é apenas quando a mente se pensa, ou seja, quando aplica sua atenção a si mesma, que ela se explicita e pode se elucidar conceitualmente.

\section{Referências}

Agostinho (2004). Confissões. Edição bilíngue latim; português. Tradução e notas de Arnaldo do Espírito Santo, João Beato e Maria Cristina de Castro-Maia de Sousa Pimentel. $2^{\text {a }}$. ed. Lisboa: Imprensa nacional-casa da moeda. (Original de 399 D.C)

Agostinho (2005). Sobre a Trindade (A. Belmonte, trad.). São Paulo: Paulus Editora. (Original publicado por volta de 416)

Aristóteles (2006). De Anima. (Trad. e notas de Maria Cecília Gomes dos Reis). São Paulo: Editora 34. (Publicado originalmente no século IV)

Cary, P. (2000). Augustine's Invention of the Inner Self: The Legacy of a Christian Platonist. New York: Oxford University Press.

Evans, G.R (1995). Agostinho: sobre o mal. São Paulo: Paulus.

Gilson, E. (2006). Introdução ao estudo de Santo Agostinho. São Paulo: Paulus. (Publicado originalmente em 1946)

Husserl, E. (1952). Ideen zu einer Reinen Phänomenologie und Phänomenologischen Philosophie: Phänomenologische Untersuchungen zur Konstitution. Zweites Buch. (Hua. 4). Haag: Martinus Nijhoff. Manuscrito de 1912.

Husserl, E. (1994). Lições para uma fenomenologia da consciência interna do tempo; trad., introd. e notas Pedro M. S. Alves. Lisboa: Impr. Nac.-Casa da Moeda.

Husserl, E. (2013). Meditações Cartesianas (trad. Pedro Alves). Rio de Janeiro: Forense. Original de 1931.

O’Daly, G. J. P. (1987). Augustine's philosophy of mind. Berkeley: University of California Press.

Ortega y Gasset, J. (1971). Que é filosofia?. Rio de Janeiro: Livro Ibero-americano.

Platão (1952). The Dialogs of Plato. Trad. Benjamin Jowett. Chicago: Encyclopedia Britannica. (Publicado originalmente na primeira metade do século IV)

Reale, A. \& Antiseri.(2003) Historia da Filosofia, 3 vols. São Paulo: Paulus. 
Rist, J. (2001). Faith and Reason. In E. Stump \& N. Kretzmann (Eds.), The Cambridge companion to Augustine. Cambridge, UK; New York: Cambridge University Press

Stein, E. (2010). Beiträge zur philosophischen Begründung der Psychologie und der Geisteswissenschaften. Freiburg: Herder (Original de 1922).

Zahavi, D. (1999). Self-awareness and alterity: a phenomenological investigation. Evanston, Ill.: Northwestern University Press.

Sávio Peres possui Graduação em Psicologia pela Faculdade de Filosofia Ciências e Letras de Ribeirão Preto da Universidade de São Paulo (FFCLRP/USP), Mestrado e Doutorado pela FFCLRP/USP, com estágio internacional na Università Lateranense (Roma). Fez pós-doutorado (2011-2014) em Filosofia pela Pontifícia Universidade Católica de São Paulo (PUC-SP), com estágio internacional no Center for Subjectivity Research (Copenhagen). Membro do GT de Fenomenologia da Associação Nacional de Pós-Graduação em Filosofia (ANPOF) e Membro do GT de Fenomenologia, Saúde e Processos Psicológicos da Associação Nacional de Pesquisa e Pós-graduação em Psicologia (ANPEPP). Pós-Doutorando na Unesp-Assis e Professor Substituto na Universidade Federal do Paraná. Email: savioperes@yahoo.com.br

Recebido em 23.01.2018

Aceito em 20.08.2018 